\title{
Efek Limbah Cair Industri Tekstil Pasca IPAL Terhadap Pertumbuhan Tanaman Kubis dan Preferensi Oviposisi Imago Plutella xylostella L.
}

\section{Siska Rasiska1), Muh. Yasin²), Ceppy Nasahi1), Syarif Hidayat ${ }^{1),}$ dan Oviyanti Mulyani ${ }^{3)}$}

1) Departemen Hama Penyakit Tanaman, Fakultas Pertanian Universitas Padjadjaran 2) Alumni Program Studi Agroteknologi Fakultas Pertanian, Universitas Padjadjaran 3) Departemen Ilmu Tanah dan Sumberdaya Lahan, Fakultas Pertanian Universitas Padjadjaran Jl. Raya Bandung Sumedang Km 21 Jatinangor

Korespondensi: s.rasiska@unpad.ac.id

\begin{abstract}
Treated industrial textile wastewater has organik and heavy metal compound that have toxicity effect on plant and other organism in agroecosystem. This research aimed to study the effect of industrial textile treated wastewater on cabbage growth and oviposition preference of Plutella xylostella L. The research was done at Green House in Ciparanje, Agriculture Faculty, Universitas Padjadjaran, Jatinangor District, Sumedang, West Java, Indonesia on May to June of 2018. Experimental design used was Block Randomized Design with nine treatments of industrial textile treated wastewater in various concentrations: $0 \%, 12,5 \%, 25 \%, 37,5 \%, 50 \%, 62,5 \%, 75 \%, 87,5 \%$, and $100 \%$, and three replications. This research revealted that industrial textile treated wastewater has no effect on growth of cabbage, but has an effect on oviposition of Plutella xylostella L.
\end{abstract}

Keyword: industrial textile treated wastewater, growth of cabbage, preference oviposition, Plutella xylostella $\mathrm{L}$.

\section{PENDAHULUAN}

Limbah cair industri tekstil merupakan salah satu sumber pencemar yang dapat memengaruhi produktivitas pertanian. Limbah cair industri tekstil diketahui mengandung logam berat yang bersifat toksik dan termasuk pada Bahan Beracun dan Berbahaya (B3), diantaranya cadmium (Cd), kromium (Cr), plumbum $(\mathrm{Pb})$ dan seng $(\mathrm{Zn})$ (Suhendrayatna, 2001; Long dkk, 2003).

Limbah industri tekstil juga memiliki kadar warna, Chemical Oxygen Demand (COD) dan Total Suspended Solid (TSS) yang cukup tinggi, karena sebagian besar limbah yang dihasilkan berupa campuran dari bahan bahan organik sebagai produk samping dari proses produksi (Hadiwidodo, dkk., 2009). Senyawa organik yang terkandung di dalam air yang tercemar limbah industri tekstil diantaranya adalah kalium permanganate, yang dapat digunakan oleh bakteri untuk berkembang biak (Komarawidjaya, 2016).

Beberapa perusahaan industri tekstil membuang langsung limbah cairnya ke dalam badan perairan seperti sungai tanpa melalui proses pengolahan terlebih dahulu. Limbah cair industri tekstil dengan karakteristiknya tanpa diolah terlebih dahulu dapat menjadi sumber pencemar yang berbahaya bagi lingkungan perairan maupun daratan. Air di sungai tersebut seringkali dijadikan sebagai sumber pengairan bagi pertanian. Komarawidjaya (2016) menyatakan bahwa tanah pertanian yang telah tercemar limbah industri tekstil dalam jangka waktu yang lama dan terpapar secara terus menerus mengalami proses akumulasi mengandung $\mathrm{Cr} \quad(8,56$ $\mathrm{mg} / \mathrm{L}), \mathrm{Pb}(9,06-16,64 \mathrm{mg} / \mathrm{L}), \operatorname{Ar}(8,4-13,2$ $\mathrm{mg} / \mathrm{L})$ dan Zn (2,87-92,69 mg/L).

Beberapa perusahaan telah melakukan pengolahan limbah industri tekstil terlebih dahulu sebelum dibuang ke sungai melalui proses Instalasi Pengolahan Air Limbah (IPAL). Teknologi ini dianggap telah mampu meminimalisir kandungan zat berbahaya yang ada di dalam limbah industri tekstil, agar tidak terlalu mencemari lingkungan sehingga aman bagi lingkungan.

Salah satu contoh hasil pengujian dari limbah cair industri tekstil pasca IPAL (PT. Wiska) dengan metode yang telah sesuai dengan Standar Nasional Indonesia (SNI) memiliki karakteristik limbah yang berbeda 
dengan limbah yang belum melalui proses IPAL, yaitu:

- Temperatur menurun $\left(23,4^{\circ} \mathrm{C}\right.$ menjadi $21,7^{\circ} \mathrm{C}$ )

- Padatan terlarut total (TDS) meningkat (413,7 mg/L menjadi 919,7 mg/L)

- Zat tersuspensi menurun $(232,9 \mathrm{mg} / \mathrm{L}$ menjadi $52,21 \mathrm{mg} / \mathrm{L}$ )

- pH meningkat $(7,13$ menjadi 7,77)

- Kandungan logam berat seperti Fe ( $<0,020 \mathrm{mg} / \mathrm{L}), \quad \mathrm{Mn}$ terlarut $(<0,020$ $\mathrm{mg} / \mathrm{L}), \mathrm{Cu}(<0,020 \mathrm{mg} / \mathrm{L}), \mathrm{Zn}(<0,020$ $\mathrm{mg} / \mathrm{L}), \mathrm{Cr}$ heksavalen $(<0,11 \mathrm{mg} / \mathrm{L}), \mathrm{Cr}$ $(<0,050 \mathrm{mg} / \mathrm{L}), \mathrm{Cd}(<0,030 \mathrm{mg} / \mathrm{L}), \mathrm{Pb}$ $(<0,43$ menjadi 0,43$)$, nikel $\quad<0,200$ $\mathrm{mg} / \mathrm{L})$, Co $(<0,160 \mathrm{mg} / \mathrm{L})$, sianida $(<0,50$ $\mathrm{mg} / \mathrm{L})$, dan NH3.N $(<3,75 \mathrm{mg} / \mathrm{L})$ cenderung tetap

- BOD $20^{\circ} \mathrm{C}(45,37 \mathrm{mg} / \mathrm{L}$ menjadi 16,11 $\mathrm{mg} / \mathrm{L})$, COD $(143,8 \mathrm{mg} / \mathrm{L}$ menjadi 43,51 $\mathrm{mg} / \mathrm{L}$ ) cenderung menurun

- Kandungan bahan organik seperti MBAS $(6,261 \mathrm{mg} / \mathrm{L}$ menjadi $0,617 \mathrm{mg} / \mathrm{L})$ menurun, phenol $(<0,140 \mathrm{mg} / \mathrm{L}$ menjadi $0,296 \mathrm{mg} / \mathrm{L})$, minyak dan lemak $(1,08$ $\mathrm{mg} / \mathrm{L}$ menjadi $1,12 \mathrm{mg} / \mathrm{L}$ ) cenderung meningkat.

Hasil analisis ini menunjukkan bahwa terdapat beberapa indicator zat yang mengalami penurunan, peningkatan maupun tetap. Akan tetapi, dari beberapa indicator, logam berat yang terkandung di dalam limbah industri tekstil cenderung tetap atau dengan kata lain tidak dapat di degradasi dengan cara IPAL. Tentu saja, kandungan logam berat walaupun dalam konsentrasi yang rendah dapat bersifat toksik terhadap berbagai mahluk hidup. Dengan demikian, teknologi ini memiliki beberapa kekurangan, diantaranya tidak efektif karena semakin kompleksnya limbah yang dihasilkan dan biaya operasional yang sangat tinggi. Selain itu, teknologi ini juga tidak mampu mengoksidasi senyawa organik dan zat warna (Hadiwidodo dkk., 2009).

Senyawa logam berat yang tidak dapat didegradasi melalui IPAL dapat memengaruhi lingkungan. Menurut Damayanti (2004), lingkungan yang tercemar buangan limbah industri tekstil salah satunya dapat menurunkan produktivitas tanaman. Akumulasi logam berat dapat terserap melalui akar, kemudian masuk ke jaringan tanaman (Alloway, 1990).

Tanaman yang telah tercemar limbah industri tekstil mengalami kerusakan. Umumnya tanaman yang terkena logam berat menyebabkan penurunan hasil sekitar $10 \%$, penurunan kandungan klorofil total dan mengubah jalur metabolisme dari tanaman (Kisku et al., 2000). Selain itu, akibat logam berat yang tinggi akan menimbulnya gejala menyerupai klorosis, pertumbuhan yang lambat, akar kecoklatan, terganggunya fotosistesis, gangguan terhadap siklus sel, dan lain sebagainya (Leyval et al., 2002).

Kubis (Brassica oleracea var. capitata L.) menjadi salah satu tanaman yang banyak diusahakan oleh petani. Tanaman kubis yang di peroleh di Jawa Barat dan Jawa Timur menunjukkan secara umum tercemar logam berat $\mathrm{Pb}$ (BPPDP, 2008). Menurut Sidik (2013), kandungan Cd pada konsentrasi 4,23 dan 0,018 ppm menunjukkan pertumbuhan tanaman kubis dapat dikatakan normal dan kualitas krop tergolong baik.

Menurut Shanker (2005), kandungan $\mathrm{Cr}$ yang berlebihan pada tanaman kubis dapat menghambat pertumbuhan tanaman, menyebabkan kronis pada daun muda, mengganti fungsi enzim, mengurangi pigmen tumbuh, merusak sel-sel akar, penghambatan pada klorofil, dan membran sel. Efek dari limbah yang mengandung $\mathrm{Zn}$ yang berlebihan pada pertumbuhan kubis menunjukkan gejala seperti klorosis pada daun muda, dan akar kecoklatan. Kondisi tanaman kubis yang telah tercemar logam berat juga akan memengaruhi pada perilaku hama utama. Salah satu hama utama pada tanaman kubis adalah ulat daun kubis (Plutella xylostella L.). Kehilangan hasil produksi akibat hama ini mencapai 58\%100\% (Rukmana, 1994).

Penelitian ini bertujuan untuk memelajari efek limbah industri tekstil pasca IPAL terhadap pertumbuhan tanaman kubis dan 
preferensi oviposisi serangga hama Plutella xylostella $\mathrm{L}$.

\section{METODOLOGI}

Penelitian dilaksanakan pada Maret sampai Juni 2018 di rumah kaca Fakultas Pertanian Universitas Padjadjaran, yang berlokasi di Ciparanje Jatinangor, Kabupaten Sumedang pada ketinggian $760 \mathrm{~m} \mathrm{dpl}$.

Metode penelitian yang digunakan adalah metode eksperimen dengan menggunakan Rancangan Acak Kelompok (RAK). Perlakuan terdiri atas perbedaan konsentrasi limbah cair industri tekstil pasca IPAL yang dibagi menjadi 9 taraf, yaitu: 0\% (A), 12,5\% (B), 25\% (C), 37,5\% (D), 50\% (E), 62,5\% (F), 75\% (G), $87,5 \%(\mathrm{H})$, dan $100 \%$ (I). Masing-masing perlakuan diulang sebanyak 3 kali, sehingga diperoleh 27 satuan percobaan.

Limbah industri tekstil diperoleh langsung dari pabrik tekstil yang berasal langsung dari IPAL salah satu pabrik tekstil di kawasan Desa Cipacing, Jatinangor, Kab. Sumedang. Air limbah IPAL tersebut kemudian dimasukkan ke dalam jerigen berukuran $10 \mathrm{~L}$.

Perbanyakan P. xylostella dilakukan dengan memelihara pupa yang diperoleh dari lahan kubis area Jatinangor. Pupa dimasukkan ke dalam stoples yang berdiameter $30 \mathrm{~cm}$ dengan tinggi $30 \mathrm{~cm}$ yang bagian atasnya dilubangi dan dipasang kain kasa. Tanaman kubis yang telah ditanam sebelumnya dimasukkan ke dalam toples sebagai tempat untuk bertelur.

Setelah pupa berubah menjadi imago sekira 3-6 hari, diberi pakan madu dan air yang diteteskan pada kapas yang diletakkan di dalam stoples. Imago betina akan meletakkan telur secara tunggal ataupun dalam gugusan (10-20 butir) di sekitar tulang daun pada permukaan daun kubis bagian bawah. Koloni telur yang berada pada daun dipindahkan ke stoples plastik berdiameter $15 \mathrm{~cm}$ dengan tinggi $10 \mathrm{~cm}$ dan ditutup dengan kain kasa dan dibiarkan hingga menjadi larva. Setelah 2-8 hari telur akan menetas menjadi larva yang berbentuk silindris, berwarna hijau muda dan tidak berbulu dan memiliki lima pasang proleg. Larva diberi pakan kubis yang diganti setiap hari sampai menjadi pupa.

Pupa yang terbentuk dibiarkan dalam stoples. Stoples dibersihkan dari sisa-sisa makanan larva sampai bersih tanpa diberi pakan dan dipelihara sampai menjadi imago. Imago yang terbentuk dipilih 60 ekor jantan dan 60 ekor betina, dengan ciri - ciri serangga jantan berukuran kecil, berwarna cokelat kelabu, ketika sayap menutup tampak bintikbintik kuning yang menyerupai deretan intan sebanyak tiga buah yang saling bertemu pada bagian tengah punggung dan warna tiga berlian pada sayap depan lebih terang. Ciriciri imago betina hampir sama dengan imago jantan, akan tetapi bintik yang menyerupai intan pada sayap imago betina berwarna lebih gelap dibandingkan dengan imago jantan, dan kemudian disiapkan sebagai serangga uji (Sari, 2016).

Pada saat tanaman berumur 5 minggu setelah tanam, Imago $P$. xylostella diinfestasikan ke tanaman kubis yang diletakkan dalam kurungan, sebanyak 20 pasang per kurungan. Umur imago yang di siapkan sebagai serangga uji adalah serangga yang berumur 3 hari. Dengan cara memilih 20 pasang perulangan yang terdiri dari 20 betina dan 20 jantan. Setelah itu di masukkan ke kurungan yang berukur $200 \mathrm{~cm}$ dan lebar 150 cm. Pengamatan dilakukan terhadap pertumbuhan tanaman berupa tinggi tanaman dan jumlah daun; serta perilaku hama berupa jumlah kunjungan imago P. xylostella terhadap tanaman kubis dan oviposisi dilakukan dengan cara manual yaitu dengan menghitung jumlah telur setiap tanaman.

\section{HASIL DAN PEMBAHASAN}

\subsection{Pertumbuhan tanaman kubis}

Limbah industri tekstil pasca IPAL mengandung senyawa organik dan logam berat yang dapat memengaruhi pada pertumbuhan tanaman kubis. Senyawa organik tersebut dapat digunakan oleh tanaman sebagai sumber nutrisi untuk pertumbuhan tanaman kubis. Tabel 1 
menunjukkan pertumbuhan tinggi tanaman kubis yang diberi limbah industri tekstil pasca IPAL tidak berbeda dengan tanaman kubis yang tidak diberi limbah industri tekstil dan tidak berbeda pula di antara perlakuan. Hal ini menunjukkan bahwa limbah industri tekstil tidak memengaruhi terhadap pertumbuhan tinggi tanaman kubis.

Tabel 1 Tinggi Tanaman Kubis (cm) yang Perlakuan Diberi Limbah Industri Tekstil pasca IPAL

\begin{tabular}{crrrrr}
\hline \multirow{2}{*}{ Perlakuan } & \multicolumn{5}{c}{ Hasil pengamatan tinggi tanaman (cm) } \\
\cline { 2 - 6 } & Minggu 1 & Minggu 2 & Minggu 3 & Minggu 4 & Minggu 5 \\
\hline A & $5,83 \pm 0,29 \mathrm{a}$ & $6,50 \pm 0,50 \mathrm{a}$ & $8,83 \pm 1,26 \mathrm{a}$ & $10,00 \pm 0,87 \mathrm{a}$ & $11,17 \pm 1,04 \mathrm{a}$ \\
B & $5,33 \pm 0,58 \mathrm{a}$ & $6,17 \pm 0,58 \mathrm{a}$ & $8,17 \pm 1,26 \mathrm{a}$ & $10,20 \pm 0,61 \mathrm{a}$ & $11,83 \pm 1,15 \mathrm{a}$ \\
C & $4,50 \pm 0,50 \mathrm{a}$ & $5,83 \pm 1,04 \mathrm{a}$ & $8,37 \pm 0,71 \mathrm{a}$ & $9,33 \pm 0,58 \mathrm{a}$ & $10,00 \pm 1,32 \mathrm{a}$ \\
D & $4,83 \pm 1,04 \mathrm{a}$ & $6,33 \pm 0,29 \mathrm{a}$ & $8,37 \pm 1.10 \mathrm{a}$ & $9,50 \pm 0,50 \mathrm{a}$ & $10,33 \pm 0,29 \mathrm{a}$ \\
E & $5,17 \pm 0,58 \mathrm{a}$ & $7,00 \pm 0,00 \mathrm{a}$ & $9,00 \pm 0,00 \mathrm{a}$ & $10,33 \pm 0,58 \mathrm{a}$ & $11,67 \pm 0,29 \mathrm{a}$ \\
F & $5,00 \pm 0,00 \mathrm{a}$ & $6,83 \pm 0,29 \mathrm{a}$ & $9,00 \pm 1,00 \mathrm{a}$ & $10,07 \pm 0,40 \mathrm{a}$ & $11,17 \pm 0,58 \mathrm{a}$ \\
G & $4,67 \pm 0,29 \mathrm{a}$ & $7,00 \pm 0,87 \mathrm{a}$ & $8,20 \pm 1,13 \mathrm{a}$ & $9,87 \pm 0,57 \mathrm{a}$ & $10,17 \pm 0,76 \mathrm{a}$ \\
H & $4,67 \pm 0,29 \mathrm{a}$ & $6,50 \pm 0,50 \mathrm{a}$ & $8,70 \pm 0,61 \mathrm{a}$ & $9,67 \pm 1,04 \mathrm{a}$ & $10,67 \pm 1,44 \mathrm{a}$ \\
I & $4,67 \pm 0,29 \mathrm{a}$ & $6,50 \pm 0,00 \mathrm{a}$ & $8,80 \pm 0,35 \mathrm{a}$ & $10,33 \pm 0,58 \mathrm{a}$ & $11,00 \pm 0,50 \mathrm{a}$ \\
\hline
\end{tabular}

Keterangan: Nilai rata-rata yang di tandai huruf yang sama pada kolom yang sama menunjukkan tidak berbeda nyata menurut Uji jarak Berganda Duncan Taraf 5\%

Tabel 2 menyajikan hasil pengamatan terhadap jumlah daun. Berdasarkan analisis data, perlakuan limbah industri tekstil pasca IPAL tidak berpengaruh nyata terhadap jumlah daun kubis. berbeda nyata perbedaan nyata. Hal ini diduga tanaman kubis memanfaatkan senyawa organik yang terdapat di dalam limbah cair tekstil pasca IPAL sebagai sumber nutrisinya walaupun kadarnya kecil. Indikator senyawa organik yang terkandung di dalam industri tekstil pasca IPAL adalah Methylen Blue Active Surfactant (MBAS) yang jumlahnya menurun. Senyawa lainnya dapat berupa phenol, minyak dan lemak yang kadarnya meningkat walaupun sedikit. Zat-zat organik tersebut mengandung unsur esensial yang dibutuhkan oleh tanaman.

Tabel 2 Jumlah Daun Tanaman Kubis yang Diberi Perlakuan Limbah Industri Tekstil pasca IPAL

\begin{tabular}{cccccc}
\hline \multirow{2}{*}{ Perlakuan } & \multicolumn{5}{c}{ Pengamatan Minggu ke } \\
\cline { 2 - 6 } & 1 & 2 & 3 & 4 & 5 \\
\hline A & $6,00 \pm 0,00 \mathrm{a}$ & $8,33 \pm 0,58 \mathrm{a}$ & $11,00 \pm 1,00 \mathrm{a}$ & $12,33 \pm 0,58 \mathrm{a}$ & $13,33 \pm 0,58 \mathrm{a}$ \\
B & $6,00 \pm 0,00 \mathrm{a}$ & $7,67 \pm 0,58 \mathrm{a}$ & $10,00 \pm 0,00 \mathrm{a}$ & $11,67 \pm 0,58 \mathrm{a}$ & $13,00 \pm 1,00 \mathrm{a}$ \\
C & $6,00 \pm 0,00 \mathrm{a}$ & $8,00 \pm 0,00 \mathrm{a}$ & $11,33 \pm 0,58 \mathrm{a}$ & $12,00 \pm 0,00 \mathrm{a}$ & $13,00 \pm 0,00 \mathrm{a}$ \\
D & $6,00 \pm 0,00 \mathrm{a}$ & $8,33 \pm 0,58 \mathrm{a}$ & $11,33 \pm 1,15 \mathrm{a}$ & $12,33 \pm 0,58 \mathrm{a}$ & $13,67 \pm 0,58 \mathrm{a}$ \\
E & $6,00 \pm 0,00 \mathrm{a}$ & $8,33 \pm 0,58 \mathrm{a}$ & $11.33 \pm 0,58 \mathrm{a}$ & $13,33 \pm 0,58 \mathrm{a}$ & $14,00 \pm 0,00 \mathrm{a}$ \\
F & $6,00 \pm 0,00 \mathrm{a}$ & $8,33 \pm 0,58 \mathrm{a}$ & $11,67 \pm 0,58 \mathrm{a}$ & $12,67 \pm 0,58 \mathrm{a}$ & $13,67 \pm 1,15 \mathrm{a}$ \\
G & $5,67 \pm 0,58 \mathrm{a}$ & $8,00 \pm 0,00 \mathrm{a}$ & $10,67 \pm 0,58 \mathrm{a}$ & $12,33 \pm 0,58 \mathrm{a}$ & $13,67 \pm 0,58 \mathrm{a}$ \\
H & $6,00 \pm 0,00 \mathrm{a}$ & $8,67 \pm 0,58 \mathrm{a}$ & $11,67 \pm 0,58 \mathrm{a}$ & $12,67 \pm 0,58 \mathrm{a}$ & $13,33 \pm 0,58 \mathrm{a}$ \\
I & $5,67 \pm 0,58 \mathrm{a}$ & $8,00 \pm 1,00 \mathrm{a}$ & $11,33 \pm 0,58 \mathrm{a}$ & $12,33 \pm 0,58 \mathrm{a}$ & $13,33 \pm 0,58 \mathrm{a}$ \\
\hline
\end{tabular}

Keterangan: Nilai rata-rata yang di tandai huruf yang sama pada kolom yang sama menunjukkan tidak berbeda nyata menurut Uji jarak Berganda Duncan Taraf 5\%

Menurut Hindarko (2003), bahan organik yang terkadung di dalam limbah dapat memngaruhi kehidupan organisme yang memerlukan oksigen, seperti ikan, serangga 
dan organisme lainnya. MBAS merupakan suatu metode untuk mengetahui kadar surfactant anion pada limbah dengan menambahkan zat metilen biru yang dapat berikatan dengan surfaktan. Surfaktan atau surface active agents pada umumnya terkandung di dalam deterjen yang bersifat mudah larut dalam air.

Kandungan surfaktan berfungsi dapat menghilangkan kandungan minyak dan lemak di dalam tekstil. Jika proses IPAL menyebabkan kandungan surfaktan menurun maka kandungan phenol, minyak dan lemak dapat meningkat. Kondisi ini dapat memengaruhi pertumbuhan tanaman kubis. Namun, kadarnya yang rendah menyebabkan pertumbuhan tanaman kubis tidak berbeda dengan tanaman kubis yang tidak mendapatkan bahan organik dari limbah industri tekstil.

Logam berat yang terkandung di dalam limbah cair industri tekstil pasca IPAL menunjukkan bahwa kadarnya masih dibawah baku mutu air irigasi yang tercantum di dalam Peraturan Pemerintah Republik Indonesia No 82 tahun 2001. Pada peraturan tersebut, kandungan logam yang dianggap aman secara ekosistem adalah $\mathrm{Cu}(0,03 \mathrm{mg} / \mathrm{L}), \mathrm{Cr}(0,05$ $\mathrm{mg} / \mathrm{L})$ dan $\mathrm{Cu}(0,02 \mathrm{mg} / \mathrm{L})$. Akan tetapi, kandungan $\mathrm{Cd}$ pada limbah cair industri tekstil berada di atas baku mutu air irigasi (0,01 mg/L). Menurut Sidik (2013), kandungan Cd pada pada kadar rendah menunjukkan pertumbuhan tanaman kubis dapat dikatakan normal dan kualitas krop tergolong baik. Logam berat lainnya seperti $\mathrm{Fe}, \mathrm{Mn}$ terlarut, $\mathrm{Cu}, \mathrm{Zn}, \mathrm{Cr}$ heksavalen, $\mathrm{Cr}, \mathrm{Cd}, \mathrm{Pb}$ nikel, kobalt, sianida, dan $\mathrm{NH}_{3} . \mathrm{N}$ sebagai zat non esensial untuk meningkatkan pertumbuhan tanaman. Pada umumnya, logam berat dapat bersifat toksik apabila berada pada konsentrasi yang berlebihan, terpapar secara terus menerus dan dalam jangka waktu yang lama.

\subsection{Populasi P. xylostella}

Tanaman kubis yang tumbuh secara normal dapat memengaruhi pada perilaku serangga di dalam menentukan inangnya. Untuk menentukan inangnya, serangga melakukan beberapa aktivitas yang bergantung pada kualitas maupun kuantitas kandungan senyawa primer maupun sekunder pada tumbuhan inang (Herlinda dkk., 2004). Salah satu aktivitas yang dimaksud adalah memilih untuk menentukan inang yang terbaik yang diindikasikan melalui hinggap pada tanaman kubis, seperti yang disajikan pada Tabel 3.

Tabel 1 Rata-rata Jumlah P. xylostella yang Hinggap pada Tanaman Kubis yang Terkontaminasi Limbah cair Industri Tekstil

\begin{tabular}{|c|c|c|c|c|c|c|c|c|}
\hline \multirow{2}{*}{$\begin{array}{l}\text { Perla- } \\
\text { kuan }\end{array}$} & \multicolumn{8}{|c|}{ Waktu pengamatan setelah infestasi } \\
\hline & 0,5 jam & 2 jam & 4 jam & 8 jam & 24 jam & 48 jam & 72 jam & 98 jam \\
\hline $\mathrm{A}$ & $0,71 \pm 0,00 \mathrm{a}$ & $1,17 \pm 0,44 a$ & $0,88 \pm 0,30 a$ & $0,71 \pm 0,00 a$ & $0,71 \pm 0,00 \mathrm{a}$ & $0,71 \pm 0,00 \mathrm{a}$ & $0,88 \pm 0,30 a$ & $0,88 \pm 0,30 a$ \\
\hline $\mathrm{B}$ & $0,71 \pm 0,00 \mathrm{a}$ & $0,71 \pm 0,00 \mathrm{a}$ & $0,71 \pm 0,00 \mathrm{a}$ & $0,71 \pm 0,00 \mathrm{a}$ & $0,71 \pm 0,00 \mathrm{a}$ & $1,00 \pm 0,50 \mathrm{a}$ & $0,88 \pm 0,30 a$ & $0,88 \pm 0,30 \mathrm{a}$ \\
\hline $\mathrm{C}$ & $1,00 \pm 0,50 \mathrm{a}$ & $1,05 \pm 0,30 \mathrm{a}$ & $0,71 \pm 0,00 \mathrm{a}$ & $0,88 \pm 0,30 a$ & $0,71 \pm 0,00 \mathrm{a}$ & $0,88 \pm 0,30 a$ & $0,71 \pm 0,00 a$ & $0,71 \pm 0,00 \mathrm{a}$ \\
\hline $\mathrm{D}$ & $0,71 \pm 0,00 \mathrm{a}$ & $0,71 \pm 0,00 \mathrm{a}$ & $0,71 \pm 0,00 \mathrm{a}$ & $0,71 \pm 0,00 \mathrm{a}$ & $0,71 \pm 0,00 \mathrm{a}$ & $0,88 \pm 0,30 a$ & $0,71 \pm 0,00 \mathrm{a}$ & $0,88 \pm 0,30 \mathrm{a}$ \\
\hline $\mathrm{E}$ & $0,71 \pm 0,00 \mathrm{a}$ & $0,88 \pm 0,30 a$ & $0,88 \pm 0,30 a$ & $0,88 \pm 0,30 a$ & $0,88 \pm 0,30 a$ & $0,88 \pm 0,30 a$ & $0,71 \pm 0,00 \mathrm{a}$ & $0,71 \pm 0,00 \mathrm{a}$ \\
\hline $\mathrm{F}$ & $0,71 \pm 0,00 \mathrm{a}$ & $0,71 \pm 0,00 \mathrm{a}$ & $0,71 \pm 0,00 \mathrm{a}$ & $0,88 \pm 0,30 a$ & $1,00 \pm 0,50 a$ & $0,71 \pm 0,00 \mathrm{a}$ & $0,71 \pm 0,00 \mathrm{a}$ & $1,05 \pm 0,30 \mathrm{a}$ \\
\hline $\mathrm{G}$ & $1,05 \pm 0,30 \mathrm{a}$ & $0,71 \pm 0,00 \mathrm{a}$ & $0,88 \pm 0,30 a$ & $0,71 \pm 0,00 a$ & $0,88 \pm 0,30 a$ & $0,88 \pm 0,30 a$ & $1,05 \pm 0,30 \mathrm{a}$ & $0,71 \pm 0,00 \mathrm{a}$ \\
\hline $\mathrm{H}$ & $0,71 \pm 0,00 \mathrm{a}$ & $0,71 \pm 0,00 \mathrm{a}$ & $0,71 \pm 0,00 \mathrm{a}$ & $1,00 \pm 0,50 \mathrm{a}$ & $0,88 \pm 0,30 a$ & $0,71 \pm 0,00 a$ & $1,05 \pm 0,30 \mathrm{a}$ & $0,88 \pm 0,30 a$ \\
\hline $\mathrm{I}$ & $0,71 \pm 0,00 \mathrm{a}$ & $0,71 \pm 0,00 \mathrm{a}$ & $0,88 \pm 0,30 a$ & $1,05 \pm 0,30 \mathrm{a}$ & $0,88 \pm 0,30 \mathrm{a}$ & $0,88 \pm 0,30 \mathrm{a}$ & $0,71 \pm 0,00 \mathrm{a}$ & $0,88 \pm 0,30 \mathrm{a}$ \\
\hline
\end{tabular}

Keterangan : Nilai rata-rata yang di tandai huruf yang sama menunjukkan tidak berbeda nyata menurut Uji jarak Berganda Duncan Taraf 5\% 
Tabel 3 menunjukkan bahwa rata rata jumlah $P$. xylostella yang hinggap pada tanaman kubis yang terkontaminasi limbah cair industri tekstil pasca IPAL tidak berbeda dengan kontrol, maupun diantara perlakuan, disetiap waktu pengamatan. Hal ini menunjukkan bahwa tanaman kubis yang terkontaminasi limbah cair industri tekstil pasca IPAL tidak memengaruhi pada aktivitas hinggap serangga $P$ xylostella. Selain itu, menurut Rahmini (2012), kesesuaian serangga terhadap tanaman inang bergantung pada kualitas nutrisi, zat pertahanan kimia tumbuhan dan lingkungan mikro.

\subsection{Preferensi Oviposisi}

Indikator lainnya dari ketertarikan serangga untuk menentukan inangnya adalah melalui proses oviposisi. Oviposisi adalah proses peletakkan telur oleh serangga pada posisi dan habitat yang cocok. Setiap serangga memiliki karakteria tempat untuk meletakkan telur yang berbeda-beda. Hal tersebut dapat di pengaruhi oleh preferensi serangga terhadap faktor fisik dan kimia yang terkandung oleh tanaman. Oviposisi akan berbeda pada bagian batang, daun, tangkai daun, tulang daun, permukaan atas daun dan bagian bawah daun (Sari, 2006).

Berdasarkan pada jumlah rata-rata telur yang dihasilkan, maka terdapat perbedaan yang nyata antara perlakuan dan control maupun diantara perlakuan, seperti yang disajikan pada Tabel 4. Perlakuan tanaman kubis yang terkontaminasi limbah cair industri tekstil pasca IPAL pada konsentrasi $100 \%$ mampu menarik serangga $\mathrm{P}$ xylostella untuk bertelur dengan jumlah rata-rata telur terbanyak. Hal ini diduga tanaman kubis yang terkontaminasi limbah cair tekstil pasca IPAL dengan konsentrasi 100\% memiliki kualitas yang lebih baik dalam hal kandungan nutrisinya yang sangat dibutuhkan oleh serangga untuk perkembangbiakannya. Menurut Ulmer dkk, (2002) bahwa nutrisi pada tanaman dapat menentukan kualitas dan kuantitas makanan untuk menunjang proses fisiologi yang berkaitan dengan pertumbuhan dan perkembangan serangga.

Tabel 2 Nilai rata-rata Oviposisi

\begin{tabular}{cc}
\hline Perlakuan & Oviposisi \\
\hline $\mathrm{A}$ & $19,33 \pm 4,73 \mathrm{a}$ \\
$\mathrm{B}$ & $22,67 \pm 17,39 \mathrm{~b}$ \\
$\mathrm{C}$ & $23,67 \pm 22,03 \mathrm{~b}$ \\
$\mathrm{D}$ & $20,67 \pm 16,50 \mathrm{~b}$ \\
$\mathrm{E}$ & $25,67 \pm 18,77 \mathrm{~b}$ \\
$\mathrm{~F}$ & $30,33 \pm 26,50 \mathrm{~b}$ \\
$\mathrm{G}$ & $13,33 \pm 9,61 \mathrm{a}$ \\
$\mathrm{H}$ & $15,67 \pm 1,53 \mathrm{a}$ \\
$\mathrm{I}$ & $44,00 \pm 50,59 \mathrm{c}$ \\
\hline Keterangan: Nilai rata-rata yang di tandai huruf \\
\multicolumn{3}{c}{ yang sama menunjukkan tidak } \\
berbeda nyata menurut Uji Duncan \\
taraf 5\%
\end{tabular}

\section{KESIMPULAN}

Limbah cair industri tekstil pasca IPAL tidak memengaruhi terhadap pertumbuhan tanaman kubis. Tanaman kubis yang terkontaminasi limbah cair industri tekstil pasca IPAL tidak memengaruhi pada ketertarikan serangga untuk hinggap. Akan tetapi, tanaman kubis yang terkontaminasi limbah cair industri tekstil pasca IPAL dapat memengaruhi pada oviposisi serangga $\mathrm{P}$ xylostella.

\section{DAFTAR PUSTAKA}

Alloway, B.J, 1990. Heavy Metals in Soil. Jhon Willey and Sons Inc, New York.

Herlinda, S., R. Thalib, dan R. M. Saleh. 2004. Perkembangan dan preferensi Plutella xylostella L. (lepidoptera: plutellidae) pada lima jenis tumbuhan inang. Hayati 11 (4) : 130 - 134.

Herlinda, S. 2004. Dinamika interaksi parasitoid dengan inangnya, Plutella xylostella (lepidoptera: plutellidae) pada sayuran brassicaceae. Agria 1(1) : 10 - 17 
Kisku, G., Barman, S., \& Bhargava, S. 2000. Contamination of soil and plants with potentially toxic elements irrigated with mixed industrial effluent and its impact on the environment. Water, Air, \& Soil Pollution, 120 (1): 121-137.

Komarawidjaja, W. 2016. Sebaran limbah cair industri tekstil dan dampaknya di beberapa Desa Kecamatan Rancaekek Kabupaten Bandung. Jurnal Teknologi Lingkungan, 17 (2):

Komarawidjaja, W 2017. Paparan Limbah Cair Industri Mengandung Logam Berat pada Lahan Sawah di Desa Jelegong, Kecamatan Rancaekek, Kabupaten Bandung

Leyval, C. Turnau, K. \& Haselwwandter K. 2002. Effect of heavy metal pollution on mycorrhizal colonization and function: physiological ecological and applied aspect. Mycorrhiza 7,139-153

Rahmini., Hidayat, P., Ratna, E.S. 2012. Respon Biologi Wereng Batang Cokelat Nilaparvata logens stal (Hemiptera: Delphacidae) Terhadap Tujuh Varietas Tanaman Padi. Sekolah Pasca Sarjana. Institut Pertanian Bogor

Rukmana, R. 1994. Budidaya Kubis dan Brokoli. Kanisius, Yogyakarta. Hal : 27

Sari, D. Diana. 2016. Preferensi oviposisi Plutella xylostella (Linn.) (Lepidoptera : Plutellidae) pada tanaman Brassicaceae. Sainmatika 13 (1) : 5259.

Ulmer B, Gillott C, Woods D, Erlandson M. 2002. Diamondback moth, Plutella xylostella L, feeding and oviposition preferences on glossy and waxy Brassica rapa (L.) lines. Crop Protection 21:327-331. 